\title{
The use of statistical parameters in medical IR-image analysis
}

\author{
by I. Benkő ${ }^{1}$, G.J. Köteles ${ }^{2}$ and G. Németh ${ }^{3}$ \\ ${ }^{1}$ Budapest University of Technology and Economics (BME), Department of Energy, \\ H-1521 Budapest, Hungary; \\ 2"Frédéric Joliot-Curie” National Research Institute for Radiobiology and Radiohygiene, \\ H-1775 Budapest, POB.101.,Hungary; \\ ${ }^{3}$ Semmelweis University, Dept. of Radiotherapy, H-1389 Budapest, POB.112, Hungary.
}

\begin{abstract}
A worldwide experience has shown that many of the incidents and accidents caused by radiation sources involve only partial body irradiations and the extremities are the most frequently injured parts of the body. In the recent decade we have investigated the applicabilities of various thermographic techniques in diagnosis of radiation injury $[1,6,9]$. The present paper is dealing with two general mathematical methods of evaluation. The first is the evaluation of statistical methods for the description of temperature distribution (e.g. histographic processing, distribution curve of the histogram). The second one is the application of the distribution curve of temperature histogram for process monitoring.
\end{abstract}

\section{Introduction}

Histographic analysis is the usual mode of processing experimentally and otherwise obtained sets of data, but it may be considered as an efficient way for describing temperature fields, too. Thereby there is still little experience available for such applications and for the proper evaluation of all histogram characteristics $[4,8]$.

In determining temperature fields of various characteristics, one may choose between the following general methods, while their relative advantages and disadvantages must be decided in the light of the tests being done:

- determination the temperature distribution (Fig.1) and mean temperature in smaller specified areas of the surface (see Figs. 4,5) tested and

- application of statistical methods for the description of temperature distribution (e.g. histographic processing, distribution curve of the histogram, see Fig.2, 3).

\section{Method of statistical examination}

There are two principal methods of the histographic analysis of IR-imagery. The first is the simple methods using the parameters as maximum (max), minimum (min), average (avg) values of the temperature field in a selected area. The second one is the extended method applying the parameters as mediane (med), standard deviation (sdev), skewness (skew) and diagrams of distribution of histogram (D) and that of the density of histogram (DE) in function of temperature (Fig.2).

\subsection{Histographic processing}

The basis of the statistical analysis is the histogram of the temperature field (Fig.1). The applicabilities (advantages and limitations) of IR-images and their diagnostic and documentary values are determined in the medical practice by the following main features:

- the type of the clinical phenomenon investigated,

- consideration of rules of IR-optics during the IR-image-taking, 
- $\quad$ proper selection of ambient parameters.

Having those optimal conditions mentioned above, the IR-image will contain all important information on thermal character of the skin surface temperature concomitant to the illness. As a consequence, the evaluation of IR-images, the thermophysical characteristics and interpretation will contribute to the diagnostic value of IR-images.

Among essential values characteristic of the histograms, the following are pointed out: the highest (max), the lowest ( $\min )$ and the average (avg) temperature in the defined area; mediane (med), standard deviation (sdev) and skewness (skew); number of pixels $N(t)$ in the examined area ( $\mathrm{Ncal}$ ) and the maximum value on the ordinate of the histogram (Fmax). The relation between $N(t)$ and $n(t)$ at a given $t_{i}$ temperature is

\section{Quantitative parameters}

$$
n_{i}(t)=N_{i}(t) / \sum_{i=a}^{b} N_{i}(t)
$$

In histograms which represent temperature fields of digital IR-images, the percentages of pixel numbers $n(t)$ with the given temperature are plotted against temperatures occurring within the fields (Fig.1). Temperatures occurring in the selected area may be displayed both graphically and digitally, and the obtained data lend themselves for further computations [8]. In our practice satisfactory results were obtained when the temperature varied by tenths of degrees within the range.

\subsection{Distribution of histogram}

The distribution curve (D) of histogram is the integral of the histogram (Fig.2). By this approach sensitive measurements could be made through the value of $D$ for comparison of different cases (note: mediane is at $D=0.5$, see Table 1 ). So the definition of $D_{b}$ is

\subsection{Density of histogram}

$$
D_{b}(t)=\sum_{i=a}^{b} n_{i}(t) \text {. }
$$

The derivative of a function $D_{b}$ is the density of histogram (DE). Thus, we have

$$
D E_{b}(t)=D_{b}^{\prime}(t) \cdot d t \text {. }
$$

The density function is presented in Fig.2.

\section{Medical application}

Lacking reliable dosimetry, the physician considers the nature and severity of signs and symptoms, protracted expression of the injury, and the timing and differential expression of injury in various tissues when deciding treatment options and prognosis.

\subsection{Tissue reactions in fractionated irradiation}

The next approach in our previous researches $[5,8,10]$ was intended to reveal the minimum dose range signaling the change of local temperature following radiation injury or burns. Measurements had been initiated on oncotherapy patients submitted to accelerated electron irradiation after mastectomy (Fig.4, 5). By a computerized image analysis of the distribution of altered temperature, it was found that alterations could be detected following even a dose of $2.5 \mathrm{~Gy}$. This result is in good agreement with the previous results [3,7], i.e. even 1 or 2 Gy doses cause signs detectable by thermography. 
From the further analyses of temperature distribution curves like on Fig. 2, additional parameters could be obtained and plotted against the radiation doses fractionated by consecutive daily treatments (Fig. 3). On Table 1 the medianes of distribution curves, the temperature differences developed during the first 30 minutes after irradiation $\left(\Delta \mathrm{t}_{\text {initial }}, \mathrm{K}\right)$ and the temperature differences evolved 24 hours after irradiation $\left(\Delta t_{24 h r s}, K\right)$ are listed. Rather sensitive tissue reactions were experienced, i.e.

- during the progress of treatment the medianes of temperatures on skin surfaces increased;

- there was always an immediate reaction after irradiation, the temperature alterations $\left(\Delta \mathrm{t}_{\text {initial }}\right)$ of which was continuosly increased from appr. $0.5 \mathrm{~K}$ to more than $1 \mathrm{~K}$ following accumulated dose of $25 \mathrm{~Gy}$ but then this reaction vanished;

- within 24 hours following each irradiation the initially developed temperature has been decreased. This $\Delta \mathrm{t}_{24 \mathrm{hrs}}$ value was high after $2.5 \mathrm{~Gy}$, then deeply down-regulated despite of the next fraction and only slight decreases were detected up to $15 \mathrm{~Gy}$. Afterwards negative values, i.e. less than the temperatures before the actual irradiation appeared indicating probably the appearences of tiny necrotic areas.

\section{Conclusions}

Thermography proved to be a valuable tool to complete other diagnostic procedures for cases of local radiation injuries. The evaluation of thermogrames by computerized image analysis provided a sensitive method to detect altered temperature distribution expressed through the histograms. By this complex approach of evaluation, tissue reactions could be observed and followed (Fig. 4, 5).

In addition, numerous techniques can be utilized to evaluate circulation in an affected area and to try to determine the volume, depth, and area of tissue affected. Angiography, radionuclide imaging, and non-invasive techniques such as impedance plethysmography, magnetic resonance imaging, ultrasound. Techniques capable of evaluating superficial blood flow and tissue perfusion have clinical value for the physician who must counsel the patient and make critical decisions regarding medical or surgical treatment.

\section{References}

[1] KÖTELES, G.J., LELIK, F., SZTANYIK. L.B., "Thermographic diagnosis of radiation injury", Thermology,2, 1987; p 584-586

[2] BENKÕ, I., " Quantitative analysis of medical infrared pictures", Österreich Thermologie, 2, Sonderheft, August, 1992, p17

[3] BENKÖ, I., KÖTELES, G.J., "Thermotechnical approaches to the investigation of local injuries caused by ionising radiation", Periodica Polytechnica, Ser. Mech. Eng. 37, 1993, p 197-213

[4] BENKÕ, I., "Histographical analysis of infrared images for medical diagnosis", $8^{\text {th }}$ Int. Conf. on Thermal Engineering and Thermogrammetry, Budapest, Hungary, 1993, p 307-308

[5] BENKÕ, I., "Possibilities of infrared imagery in the field of biology of ionising radiation", Proceedings of the Workshop on Advanced Infrared Technology and Applications. Casa Malaparte - Capri (Italy), September 20-21, 1993. Fondazione "Giorgio Ronchi”, Firenze, 1994, p 255-270

[6] KÖTELES, G.J., BENKÖ, I., "Thermography in radiation injuries", Thermologie Österreich 1994; 4, p 55-65

[7] BENKÖ, I., KÖTELES, G.J., "Recent data concentring human reactions against ionizing radiation", Proceedings of the "Recent Advances in Medical Thermology". Thermologie Österreich, 4, 1994, p 181-182 
[8] BENKÕ, I., KÖTELES, G.J., NÉMETH, G., "Thermal imaging of the effects of betairradiation on human body surface”, Quantitative Infrared Thermography (QIRT '96, Stuttgart, Germany, September 2-5, 1996,. Eurotherm Series 50) Edizioni ETS, Pisa, Italy. p 354-359

[9] KÖTELES, G.J., BENKÖ, I, NÉMETH, G., "Use of thermography in diagnosis of local radiation injuries", Health Physics, 74, 1998; p 264-265

[10] BENKÖ, I., KÖTELES, G.J., NÉMETH, G., „New infrared histographic investigation of the effect of beta-irradiation in medical field", Proceedings of MIRT'98, edited by D. Balageas, G. Busse, C.M. Carlomagno and B. Wiecek, PKOptoSEP, Lodz, 1998, p 40-45

Table 1: Temperature alterations following fractionated irradiation of a chest area after mastectomy by accelerated electrons. Mediane of temperature distribution curve $\Delta t_{\text {initial }}$ and $\Delta t_{24 h r s}$ denote the temperature differences between the values before and after 30 mins. and $24 \mathrm{hrs}$, respectively.

\begin{tabular}{cccc}
\hline Dose, Gy & Mediane after 30 mins, ${ }^{\circ} \mathrm{C}$ & $\Delta \mathrm{t}_{\text {initial }}, \mathrm{K}$ & $\Delta \mathrm{t}_{24 \text { hrs }}, \mathrm{K}$ \\
\hline 0 & 32.2 & 0.6 & 2.3 \\
2.5 & 32.8 & 0.4 & -1.3 \\
5.0 & 34.9 & 0.7 & 0 \\
7.5 & 33.9 & 0.8 & 0.3 \\
10.0 & 34.0 & 1.1 & 0.3 \\
12.5 & 34.6 & 0.8 & 0.6 \\
15.0 & 34.6 & 0.9 & -0.3 \\
17.5 & 35.3 & 1.0 & 0.2 \\
20.0 & 35.1 & 0.7 & -0.4 \\
22.5 & 35.0 & 0.9 & -0.3 \\
25.0 & 34.8 & 0.2 & -1.1 \\
27.5 & 34.7 & 0.1 & - \\
30.0 & 34.5 & &
\end{tabular}

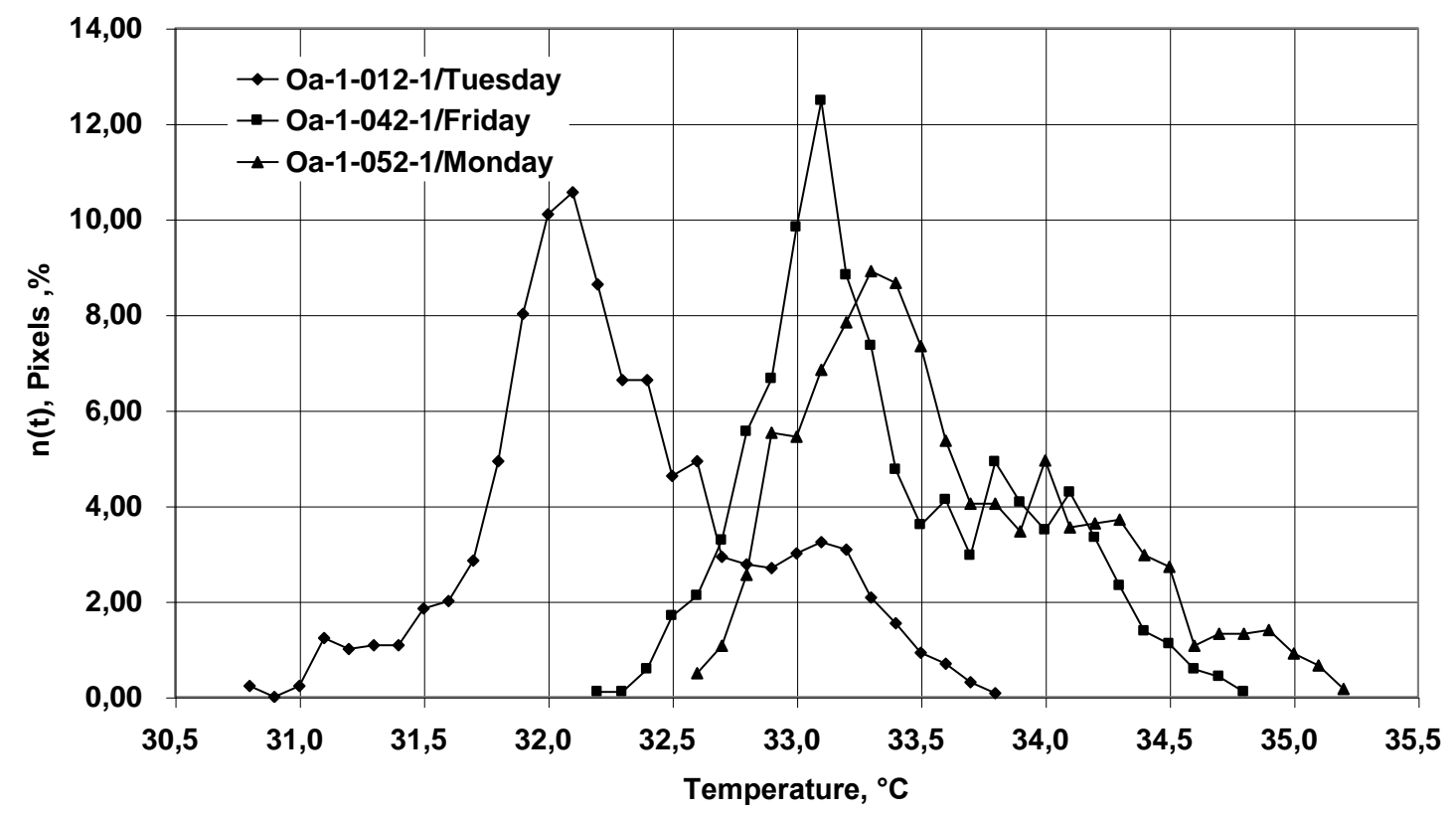

Figure 1: Series of histograms of a female chest during a radiation treatment (during and the $\underline{\text { end of first week) }}$ 


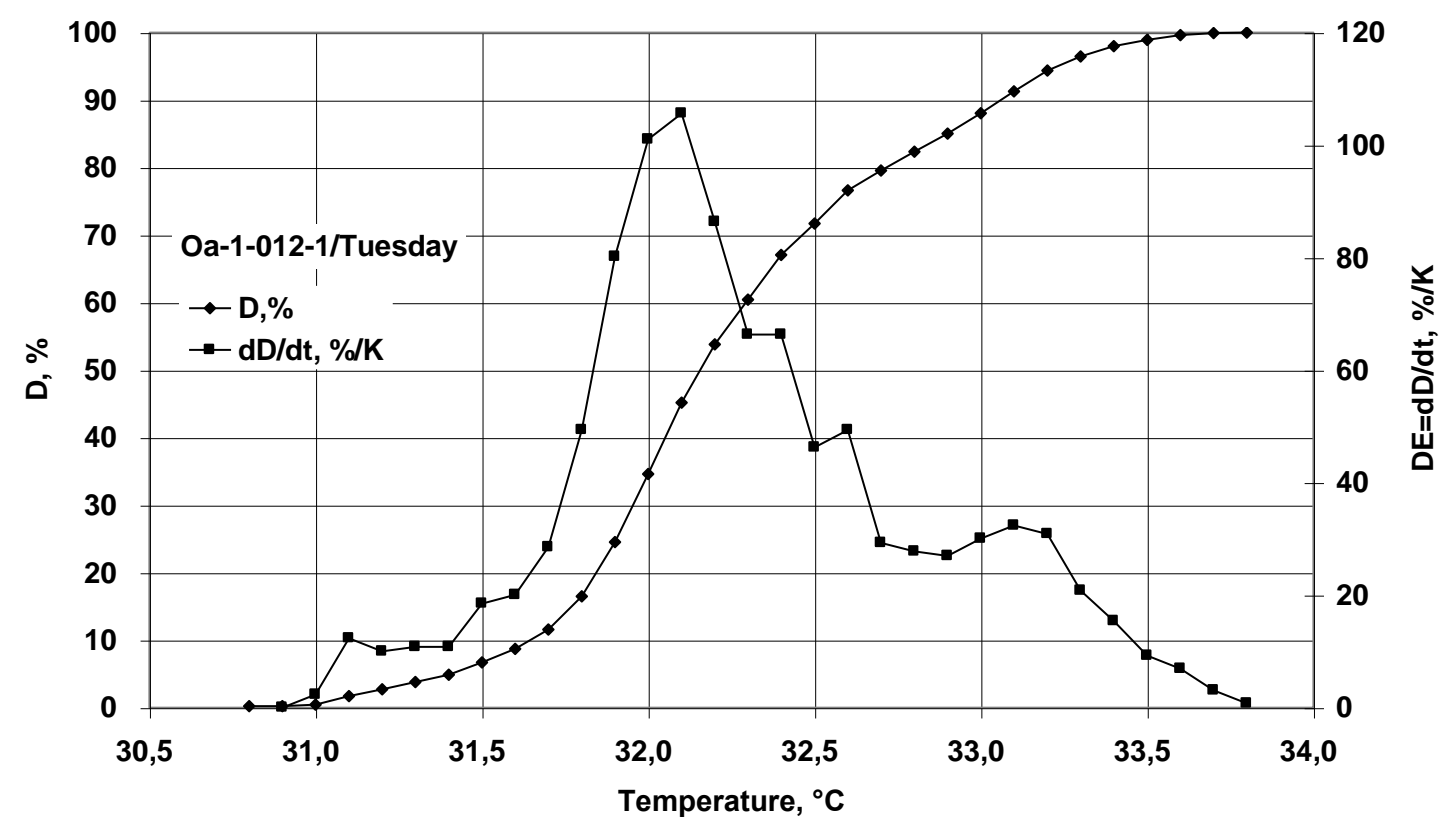

Figure 2: The distribution curve of one of the histogram (see Fig. 1) and its derivative

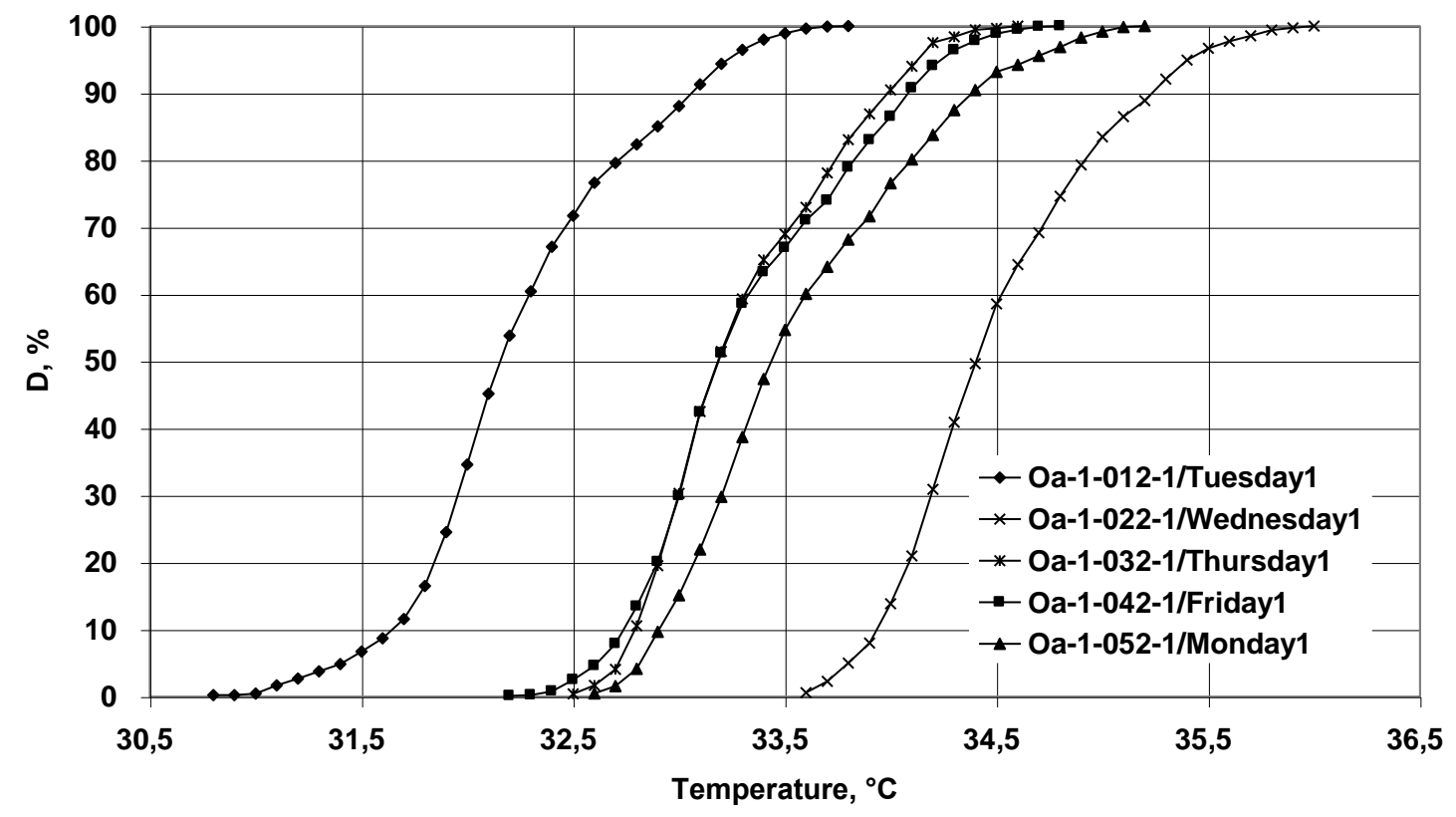

Figure 3: Process monitoring through distribution curves during and the end of the first week (see Fig. 1) 
http://dx.doi.org/10.21611/qirt.2000.001

Captions for Figs. 4-5:

Figure 4: IR-thermogram of female chest before the radiation treatment (at the beginning of the first week)

Figure 5: IR-thermogram of female chest before the treatment at the beginning of the second week 